\title{
Framework for unpacking students' mindsets in physics by gender
}

\author{
Z. Yasemin Kalender $\odot,{ }^{1}$ Emily Marshman, ${ }^{2}$ Christian D. Schunn, ${ }^{3}$ \\ Timothy J. Nokes-Malach, ${ }^{3}$ and Chandralekha Singh ${ }^{1}$ \\ ${ }^{1}$ Department of Physics and Astronomy, University of Pittsburgh, Pittsburgh, Pennsylvania 15260, USA \\ ${ }^{2}$ Department of Physics, Community College of Allegheny County, Pittsburgh, Pennsylvania 15212, USA \\ ${ }^{3}$ Learning Research and Development Center, University of Pittsburgh, Pittsburgh, \\ Pennsylvania 15260, USA
}

(Received 3 March 2021; revised 16 November 2021; accepted 17 December 2021; published 28 February 2022)

\begin{abstract}
Physics is a science, technology, engineering, and mathematics discipline in which women are severely underrepresented. Prior work has identified motivation-based explanations for low participation and retention rates of women in physics. Among various motivational factors, intelligence mindsets (i.e., having fixed or growth mindsets) have been rarely examined in the context of physics. Because physics is commonly associated with requiring brilliance to be successful, many students are likely to hold fixed mindset views for physics, which can be especially detrimental for students from underrepresented groups. We examined physics mindset views of 755 engineering and physical-science majors enrolled in calculus-based Physics 1 to understand separable aspects of such views, how these views varied by gender or sex (i.e., for female versus male students), and whether they predicted physics course grade. Multidimensional scaling analyses revealed four different mindset views that are relatively independently held beliefs. Multiple regression analyses showed that physics course grade is most closely associated with whether students deny or accept a fixed mindset view about themselves in particular. One particular view also had the largest gender difference. Therefore, understanding why students hold different mindset views and designing appropriate interventions for physics courses are important areas to consider in efforts seeking to improve outcomes in physics for diverse student groups.
\end{abstract}

DOI: 10.1103/PhysRevPhysEducRes.18.010116

\section{INTRODUCTION}

Over the last several decades, the higher education physics community in the U.S. has focused on issues related to the underrepresentation of women in the field. Although there has been some increase in women's college enrollment in physics courses in the past several decades, the percentage of physics bachelor's degrees earned by women is still only $20 \%$ [1-4]. Moreover, while some studies show that female students are doing slightly better in science, technology, engineering, and mathematics (STEM) courses [5,6], other studies of the broader pool of students taking introductory physics courses at the university level have documented differences by gender in course grades and conceptual physics tests [7-18]. Furthermore, extensive research has investigated potential causes for both representation and performance gender differences in physics and other related STEM fields [19-31]. For example, prior knowledge differences due

Published by the American Physical Society under the terms of the Creative Commons Attribution 4.0 International license. Further distribution of this work must maintain attribution to the author(s) and the published article's title, journal citation, and DOI. to differential high school experiences [19], gender biases in test questions [25], stereotype threat and ensuing anxiety $[18,26]$, and motivational factors have been found to influence learning, test performance, and career choices $[10,11,27-31]$.

With regard to motivational factors in STEM, students with positive attitudes about the learning domain (e.g., physics) tend to engage more extensively with learning activities, more often seek help from others, and have greater interest in their aptitude development in that domain despite facing setbacks [32-34]. A number of different motivational factors appear to be central to students' engagement in learning [32,35-38]. One attitudinal construct receiving a lot of attention involves students' mindsets about intelligence [39]. Dweck and colleagues' intelligence mindset theory conceptualizes students as having one of two types of intelligence mindsets: a fixed mindset (i.e., intelligence is immutable and unchangeable, you either have it or not) and a growth mindset (i.e., intelligence is malleable and can be developed through effort) [39]. Note that more recent studies have treated the two mindsets as separable rather than endpoints of a single scale [40]. Numerous studies have shown positive links between having a growth mindset and academic achievement [39-42] as well as with students' participation in 
STEM fields, especially for underrepresented students [43]. Furthermore, studies have also shown that brief interventions can change a student's mindset and yield positive outcomes even years later [44].

However, there are reasons to believe that students might have different mindset views about physics than about general academics or even other STEM disciplines, e.g., biology and chemistry [45]. For example, in addition to societal stereotypes about who belongs and can excel in physics, being a numerical minority in a classroom can further reinforce societal stereotypes about who will be more likely to succeed. General academic mindsets may not be sufficient to support students in domains with strong gender stereotypes like physics and computer science [46]. However, there has not been much focus on students' mindset views within the context of physics $[27,47,48]$. Differences by gender in intelligence mindset views may be particularly important to address as part of strategies to improve female student participation, retention, and performance. In this study, we investigated students' intelligence mindset views about learning physics. Specifically, we examined female and male students' mindset views about physics in calculus-based physics courses.

To make our approach to equity in achievement explicit, we draw upon Rodriguez et al.'s framework [49]. In particular, we focus on "equity of parity" where we investigate college outcomes and motivation but also include precollege differences in opportunity and access into our framework. Within that approach, students with different backgrounds achieving equally at the end of the instruction indicates an equitable outcome. With regard to gender or sex, we note that the prior literature has generally conflated gender with sex at birth in the past and has viewed the topic through a binary lens; recently published papers sometimes use the construction "gender or sex" to more accurately match the data used in their analyses [50].

\section{THEORETICAL BACKGROUND}

\section{A. Intelligence mindset theory}

Dweck and colleagues have extensively investigated the link between students' mindset and their learning behaviors and academic outcomes [39-48,51]. Individuals with a fixed mindset (also called an entity theory of intelligence) see intelligence as an innate and unchangeable quality, with bounded limits on potential in academic areas. By contrast, individuals with a growth mindset (also called an incremental theory of intelligence) believe that intelligence can be cultivated with practice and effort. In the original theoretical conception [39], students were thought to vary along a single continuum, from strongly growth-mindset oriented to strongly fixed-mindset oriented. We first review the literature from that perspective, and then present a new conceptualization that is more multidimensional and includes dimensions that allow for differentiation between an individual's intelligence mindset pertaining to self versus others.

Intelligence mindset theory also suggests that students vary in their views of the effort needed to succeed. In particular, depending on the mindset view (growth versus fixed), students might view effort and ability as positively related or negatively related $[52,53]$. That is, students with the growth mindset generally view the time and effort spent on a task as an opportunity for growth and to develop a skill. This positive connection can mean they are more likely to enjoy difficult problems. By contrast, students with the fixed mindset view interpret the high level of effort spent at a task as evidence of low intelligence or lack of natural talent, and therefore tend to be stressed by difficult problems.

Individuals' mindset views have also been found to influence students' engagement with an activity [39,47,54]. For instance, students with a fixed mindset are more likely to disengage, reject opportunities to learn, avoid difficult problems, and prematurely give up on challenging tasks [55]. When these students are working on a challenging problem, their available working memory resources can be reduced by anxiety during problem solving, which limits both performance and learning since working memory is limited and important to both [56-58]. On the other hand, other students with a growth mindset may experience less anxiety, be more willing to engage in challenging tasks, and be less afraid of making mistakes. They may view the mistakes as opportunities for learning and then will do better in the activities in the future and on exams [59].

Intelligence mindsets have also been connected to gender equity concerns. Overall, there are pervasive cultural biases about gender-based intellectual ability; the term "genius" (implying a fixed mindset) is commonly attributed to men [60], and children adopt these gender-based stereotypical intelligence beliefs at early ages [61]. For example, girls were more often found to avoid activities that are thought to require being "really, really smart" and to designate the male gender as being "really, really smart" [61]. Many such stereotypical attributions observed in social and academic interactions can generate a fixed mindset with varying levels across men and women.

\section{B. Intelligence mindset and academic achievement}

Growth mindset views have been found to be a statistically significant predictor of students' course achievement even after controlling for differences in relevant prior knowledge and other academic aptitude measures [62-64]. For example, Good et al. found that students in seventh grade whose mentors promoted growth mindset views achieved higher math scores in standardized tests than did those in a control group, particularly for female students, with a large Cohen' $d=1.30$ [63]. Another study found that high school students' intelligence mindset predicted students' math grades $(\beta=0.17, t=3.40$, 
$p<0.05$ ) even after controlling for their prior high school math scores [64]. A recent meta-analysis of 273 studies showed a moderate average effect size of mindset on academic outcomes, with larger effects in the domain of math and for students who were from low socioeconomic status families or were considered academically at risk [65]. Relatedly, Limeri et al. found that students' mindset views in a chemistry class shifted towards having a more fixed view, and this trend was more pronounced among students who struggled more in the course [40].

In order to promote growth mindsets for academic learning, researchers have designed and implemented a number of social-psychological classroom interventions [65-70]. The key element in these classroom interventions is acknowledging the normality and necessity of struggle to expand knowledge and skills. While these interventions aimed to help students adopt a growth mindset view, they also intend to bolster students' sense of belonging and self-confidence, especially for minoritized groups [65-70]. However, it is also important to note inconsistent outcomes across studies of these interventions and related approaches, like values affirmation interventions [69]; the aforementioned meta-analysis on mindset interventions indicates a weak average effect on students' academic outcomes [71]. It may be that the very brief interventions require follow-up components to sustain the change, that replications or scale-up studies failed to include key aspects of the intervention, or that general academic mindset is not enough in some learning domains.

Another important point is the relation between mindset and teaching approaches. In prior literature, instructors have been found to influence student mindsets and achievement [72] and their physics identity [73], particularly for students from underrepresented groups [74]. A recent study found that course grade differences by race or ethnicity were found to be twice as large in classrooms taught by the STEM faculty who endorsed a fixed mindset view than in classrooms taught by faculty who held and used a growth mindset in their teaching approaches [75]. Faculty holding fixed mindsets were often found to emphasize being smart or naturally gifted during the instruction while the faculty holding growth mindsets highlighted the significant contribution of practice and effort to students' classroom success [75].

Additionally, instructors or college admission committees holding fixed mindsets often view prior achievement differences as an indication of lack of intellectual ability [48]. By contrast, instructors holding growth mindsets recognize variations in standardized test scores as gaps in pre-college preparation due to opportunities (and not lack of growth potential), which can be eliminated by providing students positive encouragement and support as mentors [48].

\section{Intelligence mindset views in physics}

There is substantial variation by academic areas in the extent to which people believe that foundational innate talent is required for that academic area (e.g., physics, math, and philosophy are high; psychology, education, and anthropology are low), and this variation has previously been linked to underrepresentation in some STEM fields [45].

Many people assume that physics in particular requires an innate talent in order to be successful, and physics is one of the most extreme fields in terms of such stereotypes [45]. The negative stereotypes and gendered biases about who can succeed and excel in the discipline, along with the masculine culture of physics $[19,20]$, can potentially produce a fixed mindset in the general physics community, which would harm stereotyped groups. One study found that fixed mindsets were commonly adopted by graduate admission committee members in physics departments that tend to exclude women and racial minorities [20]. Therefore, physics might suffer from low gender diversity at least partly due to fixed mindset views in the field. Indeed, in a recent study of students' general and fieldspecific (i.e., physics) mindset views across gender, we found gender differences in physics-specific mindset despite seeing no such differences in students' general academic mindset [27].

\section{Unpacking intelligence mindsets-which subdimensions are critical?}

As noted previously, most prior research on intelligence mindsets has treated it as a single dimension with growth and fixed mindsets as the two endpoints. However, this is not the only logical possibility. Other motivational studies have discovered that multidimensional perspectives better account for student variation than views that assume a single dimension of opposing perspectives. For instance, in the closely linked achievement goals research area, researchers discovered that students could have both mastery and performance goals at the same time [76]. For mindsets, students could believe that both effort and ability matter, e.g., they could hold the belief that some students are missing critical capacities, but even those students who have a foundational capacity still need to exert substantial effort to develop their physics capabilities.

Moreover, stemming from stereotypes about who is brilliant and can excel in physics, it is possible that students make distinctions about themselves versus others. For example, a student from a demographic that is underrepresented in physics might be more likely to believe that some people could develop abilities through effort but they themselves could not. Conversely, a student from a demographic overrepresented in physics might be more likely to believe that they are naturally good at physics, and perhaps that most other individuals are not. Although prior measures of intelligence mindsets have included questions 
that refer to various combinations of abilities, effort, self, and others, prior researchers have not systematically analyzed these data to examine whether these dimensions are separable rather than just one overall growth versus fixed mindset dimension. For example, a study in math classes measured students' mindset with only two items focusing on the "I" related context and found significant correlations of mindset with confidence and enjoyment [77]. We note that just because prior studies have reported acceptable levels of measure reliability (i.e., Cronbach's alpha), that alone is not strong evidence of unidimensionality of the construct because correlations among separate dimensions can also produce high alphas [78].

In the mindset study presented here, we adapted previous survey items and created a few new ones iteratively and validated them for use with this population as an assessment of students' beliefs about natural talent in physics (i.e., ability) or impact of doing hard work in physics (i.e., effort) to excel [53]. Moreover, the questions are designed to determine students' mindset viewpoints about themselves (me or I) or the general population (others). As noted, studies related to achievement goal theory have shown that students can have both performance goal and mastery goal orientations simultaneously depending upon the situation [79]. In particular, in some cases, students may focus on growth of mastery in themselves (i.e., be "I" focused) but in other cases, the same students may have normative goals and may focus on performing better than others (i.e., be "other" focused in their strategies). This realization proved to be extremely productive in achievement goal theory [80]. Considering these two dimensions (effort versus ability and me versus others), we theorized the potential existence of four intelligence mindset categories (see Fig. 1). As detailed in the Sec. III, we used multidimensional scaling (MDS) [81,82] to determine whether the students also conceptually separated the items

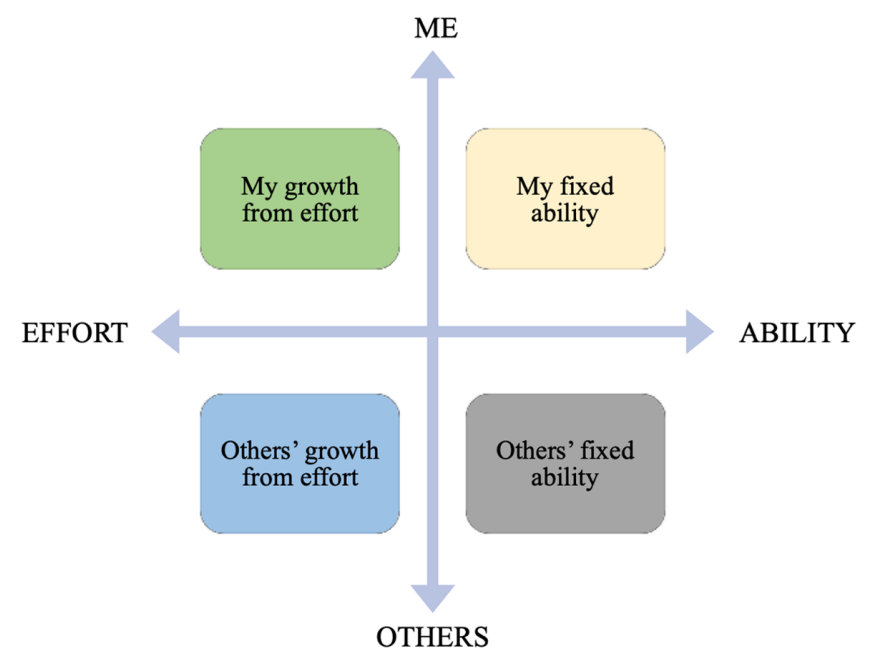

FIG. 1. The representation of the four mindset construct in two dimensions. into those four categories based upon patterns of similarity or dissimilarity in responses to individual survey questions.

A major focus of the current study is on uncovering which dimensions of physics mindset (as represented by different quadrants in Fig. 1) are most closely connected to physics course grades. Moreover, we sought to understand whether gender or sex differences in mindset are larger for a particular mindset dimension, and the extent to which those mindset differences could account for the differences in course grades between female and male students. In particular, it may be that beliefs about the self are most relevant to learning and achievement outcomes in physics since those would play a key role in determining how students react in response to challenges or struggles in the course. Consequently, endorsement of a fixed mindset about the self was hypothesized to be most indicative of nonproductive reactions to challenges.

\section{METHODS}

\section{A. Participants and course context}

A total of 755 students across four sections of introductory calculus-based Physics 1 completed the course and around $\sim 630$ of them participated in either of the pre- or postsurvey. Students who enrolled in these courses were predominantly physical science or engineering majors. Students' demographic information was obtained via university records as deidentified but linkable data (i.e., demographic and survey data were linked via a research ID created by an honest broker). This approach provided complete and accurate data on many measures that might have biases if self-reported (e.g., high school GPA), it limits categories to the ones that the university collects, which is heavily influenced by U.S. federal reporting requirements (e.g., simple racial or ethnic categories, and a conflated gender or sex binary variable). We acknowledge the harm that such data collection practices cause [83], and we are pleased to report that our university has recently switched to collecting gender information using more than binary options. Given the limitations of the data source, the patterns will predominantly reflect patterns of cis-gendered women and men. However, we use the data collected by the university (i.e., the options provided were female and male while labeled as gender) and refer to this variable as gender or sex in our analysis and results sections [50].

On the basis of the university-supplied data, female students comprised $37 \%$ of the cohort, mirroring female enrollment rates across years in this calculus-based physics course at the university. Given that this particular physics course is mostly taken by first-year engineering students at our institution, the ratio of female to male students aligns more broadly with the percentages of engineering bachelor degrees awarded to women in the U.S. [84], (p. 14). In terms of ethnic or racial distribution, the cohort consists of $79 \%$ White, $10 \%$ Asian, 2\% Black, 4\% 
Hispanic, 4\% Multiracial, and 1\% others (i.e., American Indian, unknown, etc.). The mean student age at the time of completing the pretest survey was $18.7(\mathrm{SD}=1.4)$, since this course was typically taken by first-year students and the majority of the students in this institution attend university immediately after high school.

This course covers introductory-level physics subjects such as kinematics, forces, energy and work, rotational motion, and gravitation. There was some small variation in the pedagogy across the four different instructors, but they predominately used traditional lecture-based instruction.

\section{B. Measures}

\section{Physics intelligence mindset}

A mindset survey (see Table IV in Appendix) was initially developed as part of a larger motivation survey [27] by adapting three questions from a previous general intelligence mindset survey for the physics context and revalidating the survey at our institution $[39,85]$. We administered the survey during recitations. Graduate teaching assistants handed out the survey in the first and last recitations of the semester (approximately 1-2 weeks before students take final exam) and students marked their responses on a scantron sheet. Approximately 17\% of students' survey responses were missing pre and post. Based upon the time taken during individual interviews while validating the survey, we estimate that completing the mindset items generally took 2-3 min for students.

Performing analysis on this first short-form survey, we found gender differences in physics-related mindset, but not in general intelligence mindset [27]. Based upon these findings, we expanded the number of physics-related mindset questions and validated the survey again. The survey items, shown in Table IV in Appendix section, involved a four-point Likert scale of strongly disagree to strongly agree, recoded as 1 to 4 , with questions $2,4,5$, and 7 reverse coded so that higher numbers represent mindsets that are more supportive of learning (i.e., endorsing growth mindsets and rejecting fixed mindsets). To validate our survey as a physics mindset measure in our context, we conducted interviews with 12 undergraduate students who took introductory-level physics courses, to ensure that students interpreted the items as designed. We also tested validity of the measures in this context using survey responses in a prior semester; we performed exploratory and confirmatory factor analyses to establish that the physics mindset questions cohered with each other and separated from other constructs such as physics selfefficacy, interest, and identity.

Although some psychometric analyses supported using the physics mindset questions as a single scale (e.g., a sufficiently high Cronbach $\alpha$, a measure of internal reliability), the exploratory factor analyses also provided some support for separation. Inspired by these exploratory factor analysis results and conceptual reanalysis of the contents of the survey questions, we hypothesized that there are four different groups for physics mindset items based on the referent (me versus others) and context (ability versus growth) of each question: Denying my ability is fixed—my ability, denying others' ability is fixed—others' ability, believing my intelligence can grow-my growth, and believing other's intelligence can grow-others' growth. For example, item 6 (Q6) - "If I spend a lot of time working on difficult physics problems, I can develop my intelligence in physics" was placed in the My growth group, while Q1-“Anyone can become good at solving physics problems through hard work" was placed in the Others' growth mindset construct. During the survey validation process, students showed they thought of the mindset survey items that do not have "I" as pertaining to other individual's ability or effort. After we grouped the related mindset items, two mean scores were obtained for each of the four mindset constructs: a prescore and a postscore.

\section{Prior academic performance}

From university records, we also obtained pre-college test scores that are generally good predictors of academic performance in first-year college STEM courses: SAT Math scores (200-800; 15\% missing) and high school grade point average (HS GPA, 1-5 scale when including advance courses; 0\% missing). In this data, students' SAT math scores ranged from a minimum score of 430 to a maximum score of 800 . We removed five outliers for HS GPA that were smaller than 2.5 or higher than 5 since they likely represented students coming from a different grading system. We winsorized $[86,87]$ the outliers in SAT math scores by replacing them with the 2 standard deviation cutoff value (i.e., keeping the direction of their differences but reducing the extreme extent of the difference).

\section{Course grade}

Institutional data also provided us with each student's course grade in grade point units at the end of the semester, which we used as the students' achievement outcome for the current study. The final course grade in every course section was largely based on students' midterm and final exam scores $(\sim 70 \%)$; the rest of the grade was based upon weekly homework, participation in recitation, concept quizzes, attendance, and quizzes given during recitations. The policy regarding grade points at this university are given in Table I.

Course grade is an important achievement outcome that has high external validity for students. Physics 1 grades determine whether students can go on to the next physics course and, at a finer grain size, they are a good predictor of performance in a number of related courses [88]. Students also draw their self-efficacy from such salient performance measures [89] and it influences their overall GPA and STEM-GPA, which matter for scholarships and 
TABLE I. Course letter grades and corresponding grade points.

\begin{tabular}{|c|c|c|c|c|c|c|c|c|c|c|c|c|}
\hline & $\mathrm{F}$ & $\mathrm{D}-$ & $\mathrm{D}$ & $\mathrm{D}+$ & $\mathrm{C}-$ & $\mathrm{C}$ & $\mathrm{C}+$ & $\mathrm{B}-$ & B & $\mathrm{B}+$ & $\mathrm{A}-$ & $\mathrm{A} / \mathrm{A}+$ \\
\hline $\begin{array}{l}\text { Grade point } \\
\text { Definitions }\end{array}$ & $\begin{array}{c}0 \\
\text { Failure }\end{array}$ & 0.75 & 1.00 & 1.25 & 1.75 & $\begin{array}{c}2.00 \\
\text { Minimum level } \\
\text { to graduate }\end{array}$ & 2.25 & 2.75 & $\begin{array}{l}3.00 \\
\text { Adequate level } \\
\text { to graduate }\end{array}$ & 3.25 & 3.75 & $\begin{array}{c}4 \\
\text { Superior } \\
\text { attainment }\end{array}$ \\
\hline
\end{tabular}

applications to graduate school. Course grades, especially when based heavily on high-stakes exams, can be systematically biased as a learning measure [90]. One additional concern about using course grade involves variability in instructors' assessment and grading practices. Therefore, we also included an analysis that controls for different sections (taught by a different instructor).

\section{Analysis}

In all of the following analyses, we used $\mathrm{R}$ software to clean data, plot the data to look for outliers and appropriate distributions for the given analytic methods, and conduct inferential statistical tests on our research questions. The data were approximately normal and the assumption of heterogeneity of variance across groups was not significantly violated, and thus these key assumptions of the statistical tests were met. Although the student data are inherently nested with class section, the nesting effects (performance of students influencing each other) are usually small in large lecture classes, the interclass correlations at the class level were low, and the patterns of results were similar across class sections. Therefore, we do not implement more complex multilevel models in the reported analyses, and instead simply include dummy codes for class sections in the analyses.

\section{Grouping mindset questions}

To validate the separation of the mindset questions into the hypothesized four groups along two separable dimensions, we analyzed students' pretest means on each subscale using MDS [91], testing 1-3 dimensional solutions, overall and separately by gender or sex, to ensure consistent structure. MDS produces a map of constructs based on the pattern of intercorrelations among the measures, in which distance among items is inversely proportional to the correlation strength between items. We used the MASS (isoMDS) package in $\mathrm{R}$ software to perform the MDS. MDS results are evaluated using a stress value that illustrates the goodness of the fit (i.e., the extent to which the physical distance in the plot exactly recreates the pairwise correlation distance between each of the subscales) [91]. A stress value closer to zero indicates a better fit of the model, and common standards are 0.200 poor, 0.100 fair, 0.050 good, 0.025 excellent, and 0.00 perfect [91].

\section{The differences between female and male students}

We performed a MANOVA to test for significant pre and post mean differences across the four physics mindset constructs between female versus male students, where gender or sex was the independent variable and the four physics mindset constructs were the dependent variables. Furthermore, independent $t$ tests between the two groups (i.e., female versus male students) were conducted on Physics 1 grades to first establish an outcome difference and then also on students' SAT Math and HS GPA to identify possible confounding factors in academic resources that may also influence grades. We used an $\alpha$ level of 0.05 for all statistical tests and Cohen's $d$ to represent effect sizes. The effect size ranges used were as small $(d=0.2)$, medium $(d=0.5)$, and large $(d=0.8)$ [92]. Given the $N$ 's involved, the power was $99.9 \%$ for detecting mediumeffect sizes and $68 \%$ for detecting small effect sizes in the gender or sex contrasts.

\section{Predicting physics 1 course grade}

We computed simple correlations of various potential predictors with grades and then several multiple regression analyses in order to uncover the best model for predicting students' grade in the Physics 1 courses. The first three regression models (1a, 1b, 1c) predicted students' Physics 1 grade by using only demographic information (i.e., gender or sex), prior academic performance (i.e., SAT Math, HS GPA) and all mindset groups, respectively. Our intention is to test each group's association to students' learning outcomes in the course, separately before we integrate them in the following models. In model 2, students' gender or sex and prior academic scores are run together to test whether there was a difference between female and male students' Physics 1 grades after we controlled for differences in academic resources. In model 3, we added whichever mindset construct was the strongest correlate of students' grades. We also calculated how each mindset construct correlates with one another to make sure they could reasonably be entered together in a multipleregression model (see Fig. 3). In model 4, we added all the mindset constructs as predictors as a robustness test. Standardized regression coefficients are used to represent effect sizes. Finally, we included the course section (each section has a different instructor) as a predictor in the last regression model (model 5) to address potential confounds of course effects on both mindset and grades. 


\section{RESULTS}

\section{A. Multidimensional scaling (MDS)}

The two-dimensional model produced a near perfect fit to the data based on the stress values, with a stress value of $\sim 0.00\left(1.96 \times 10^{-12}\right)$. By contrast, the one-dimensional model only converged to 0.16 , indicating a fair but not good fit. Since the two-dimensional fit was essentially perfect, there was no advantage to adding a third dimension (higher than 0.20 considered as not a good fit) [91]. Analyzing the data separately for both female and male students produced similar models. The results from the two-dimensional model for all students are presented here (see Fig. 2). The four groups cleanly fell into their own quadrants as expected by referent ( $y$ axis) and context ( $x$ axis). That is, all four mindset constructs measured different aspects of students' mindset and they are related to each other as hypothesized, i.e., along two different dimensions: effort versus ability and me versus others. This best-fitting model was replicable: A similar two-dimensional solution was obtained using post-test means as well as with a similarly large dataset using this survey in the same physics courses the year before.

Figure 3 presents the correlations between the four mindset constructs at pre and at post, as well as the prepost correlations within a mindset construct. The four mindset constructs are more correlated with each other at post than at pre, but even at post none of the constructs are so highly correlated as to be considered redundant. The pre-post correlations of each construct show moderate stability. This moderate level of stability is consistent for a construct that is hypothesized to both support learning (i.e., not have too low a pre-post stability) and be influenced by instructional experiences (i.e., not have too high a prepost stability).

\section{B. Differences in mindsets, prior academics, and physics grades by students' gender or sex}

Table II shows descriptive statistics for each measure for all the students. In the Table V and Fig. 5 in the Appendix section, we also report the pre and post average mindset scores for students who participated in both pre and post survey. Change patterns are the same across both approaches to studying pre-post change, and the pre means are approximately the same across all those who had pre data and only those who had pre and post. Therefore, we proceeded with using the complete cases in our $t$-test analysis (see Fig. 4).

The MANOVA conducted on the relationship of gender or sex to each mindset construct indicated a significant multivariate effect of gender or sex: Male students had significantly higher scores across mindset constructs

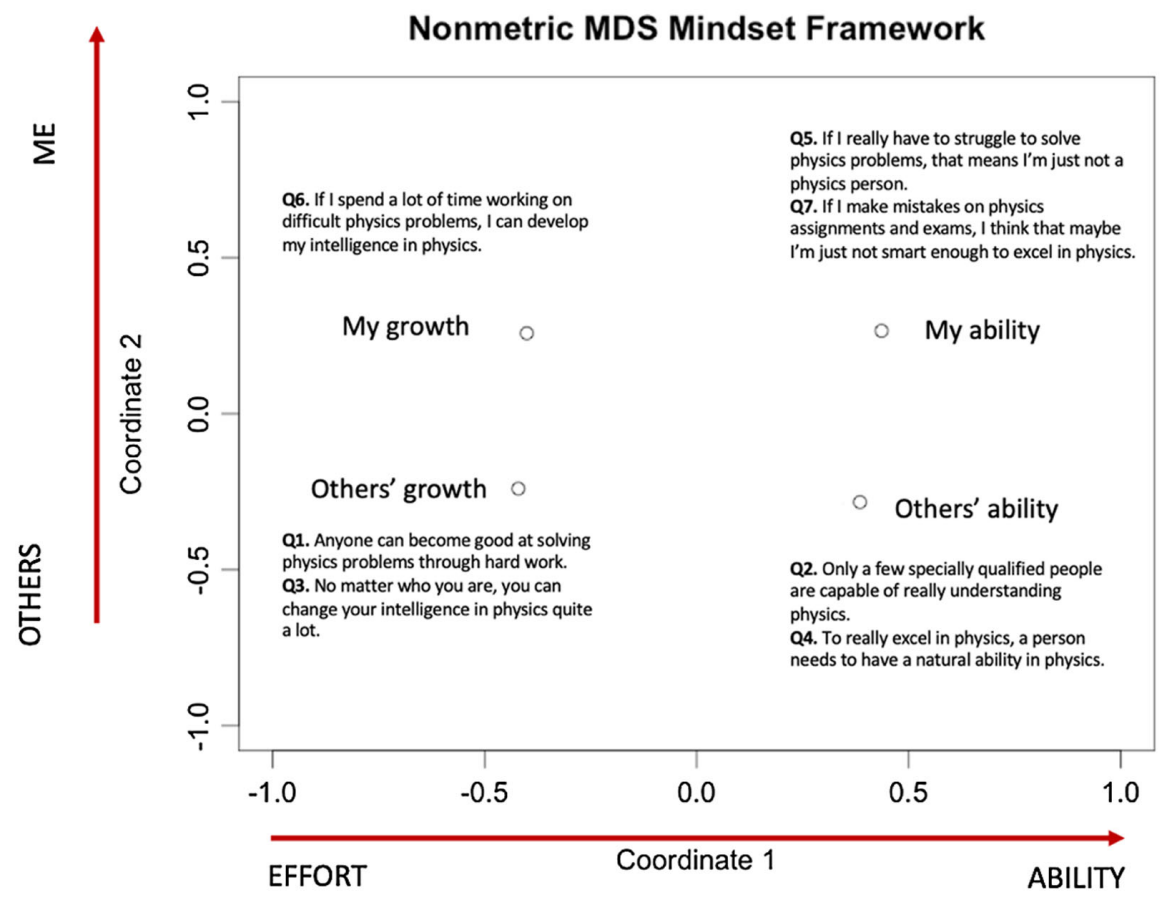

FIG. 2. The two-dimensional MDS results for the four pre mindset constructs, along with the questions forming each group. The circles are for the constructs, which are based on the average of the items for the construct. MDS is given a dataset of pairwise distance between each construct and finds a best fitting solution (in which pairwise distances among points recreate the pairwise distances that were input). The plotted distances are the same scale as the input distances (i.e., the inverse of correlations among constructs). The zero point and rotation of the plotted axes is arbitrary. 


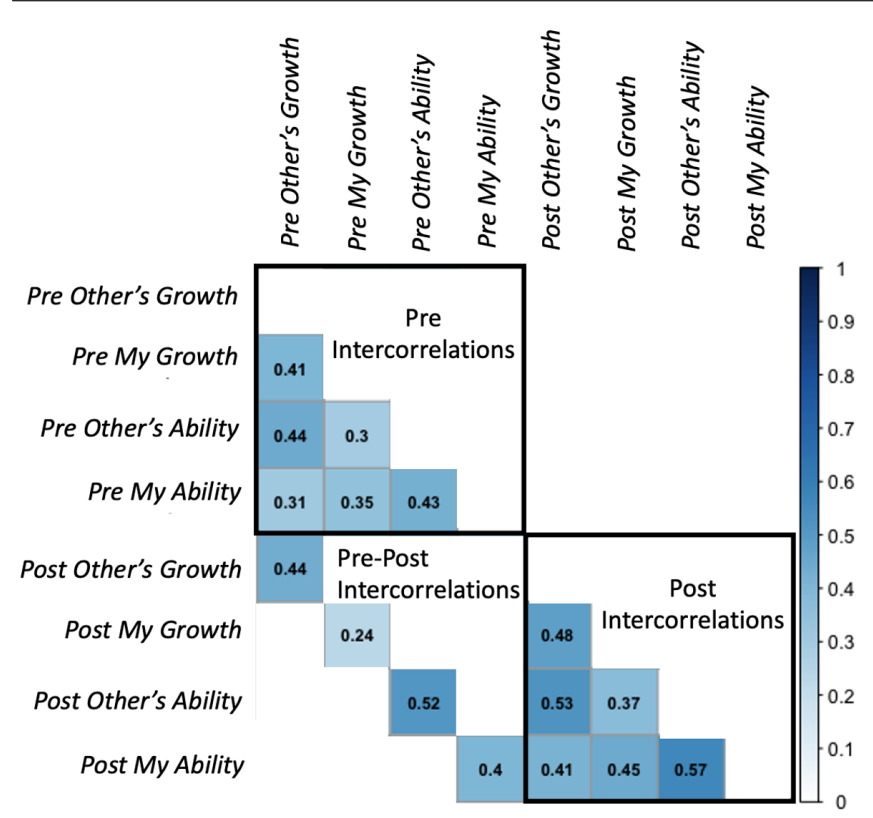

FIG. 3. Pearson correlation values among the four mindset constructs at pre and post, and pre-post correlations within each group. All presented correlations are statistically significant at $p<0.001(N=514)$.

$[F(1,642)=6.82, p<0.001]$. In the follow-up $t$-test analyses, all four mindset constructs showed statistically significant differences, with male students having higher mindset scores than female students at both pre and post (see Fig. 4). In the pre survey, the largest gender or sex difference was for the "denying my ability is fixed" (my ability) group $(d=0.31)$, which indicates that female students were more likely to believe that having an "ability" was necessary to be successful in physics than male students. This difference in mean my ability values was even larger in the post-test $(d=0.46)$. All other mindset gender or sex differences were either not significant at pre and then significant but small at post (others' ability, others' growth), or equally small at both pre and post (my growth).

There was a small difference in Physics 1 grade by gender or sex with female students having lower grades than male students $(d=0.15, p=0.049)$. Compared to male students, female students in this course context have almost equivalent SAT Math scores $(d=0.11$, $p=0.09)$ and noticeably higher average overall HS GPAs $(d=-0.48, p<0.001)$. In other words, when accounting for prior academic performance alone, the expectation would be for male students in this sample to have lower physics course grades, just as they have lower grades in other STEM courses [5,6]. Such a pattern of nearequal performance despite stronger prior academic preparation motivates the need to uncover motivational or experiential differences.

\section{Correlations among variables and predicting physics course grade}

Overall, the potential mindset predictors were not strongly correlated with the academic resource predictors (at pre or post). Among the few statistically significant predictors, SAT Math was slightly correlated with post others' ability and post my ability groups, with $r=0.14$ and $r=0.17$ respectively. HS GPA did not show any significant correlation with any variables except SAT Math $(r=0.25)$. Thus, these physics mindsets do not appear to be derived from prior overall academic performance, which is consistent with the prior work finding that general intelligence mindsets were distinct from physics-specific mindsets [27].

TABLE II. Mean, SD, and $N$ for each mindset construct at pre and post (SAT Math, HS GPA, and Physics 1 grade) by gender or sex.

\begin{tabular}{|c|c|c|c|c|c|}
\hline & & \multicolumn{2}{|c|}{ Female } & \multicolumn{2}{|c|}{ Male } \\
\hline & & Mean & $\mathrm{SD}$ & Mean & $\mathrm{SD}$ \\
\hline \multicolumn{6}{|c|}{ Mindset groups } \\
\hline PRE & My ability & 2.96 & 0.51 & 3.12 & 0.52 \\
\hline$N=646-648$ & My growth & 3.29 & 0.60 & 3.40 & 0.60 \\
\hline & Others' ability & 2.94 & 0.60 & 2.92 & 0.65 \\
\hline & Others' growth & 3.06 & 0.56 & 3.05 & 0.58 \\
\hline POST & My ability & 2.63 & 0.61 & 2.91 & 0.59 \\
\hline$N=623-628$ & My growth & 3.10 & 0.63 & 3.22 & 0.63 \\
\hline & Others' ability & 2.70 & 0.65 & 2.80 & 0.70 \\
\hline & Others' growth & 2.86 & 0.59 & 3.03 & 0.62 \\
\hline \multicolumn{6}{|c|}{ Prior academic scores and college grades } \\
\hline$N=626$ & SAT Math (510-800) & 699 & 56 & 706 & 51 \\
\hline$N=748$ & HS GPA (2.5-5) & 4.25 & 0.34 & 4.09 & 0.41 \\
\hline$N=748$ & Physics 1 grade $(0-4)$ & 2.24 & 1.00 & 2.39 & 1.04 \\
\hline
\end{tabular}




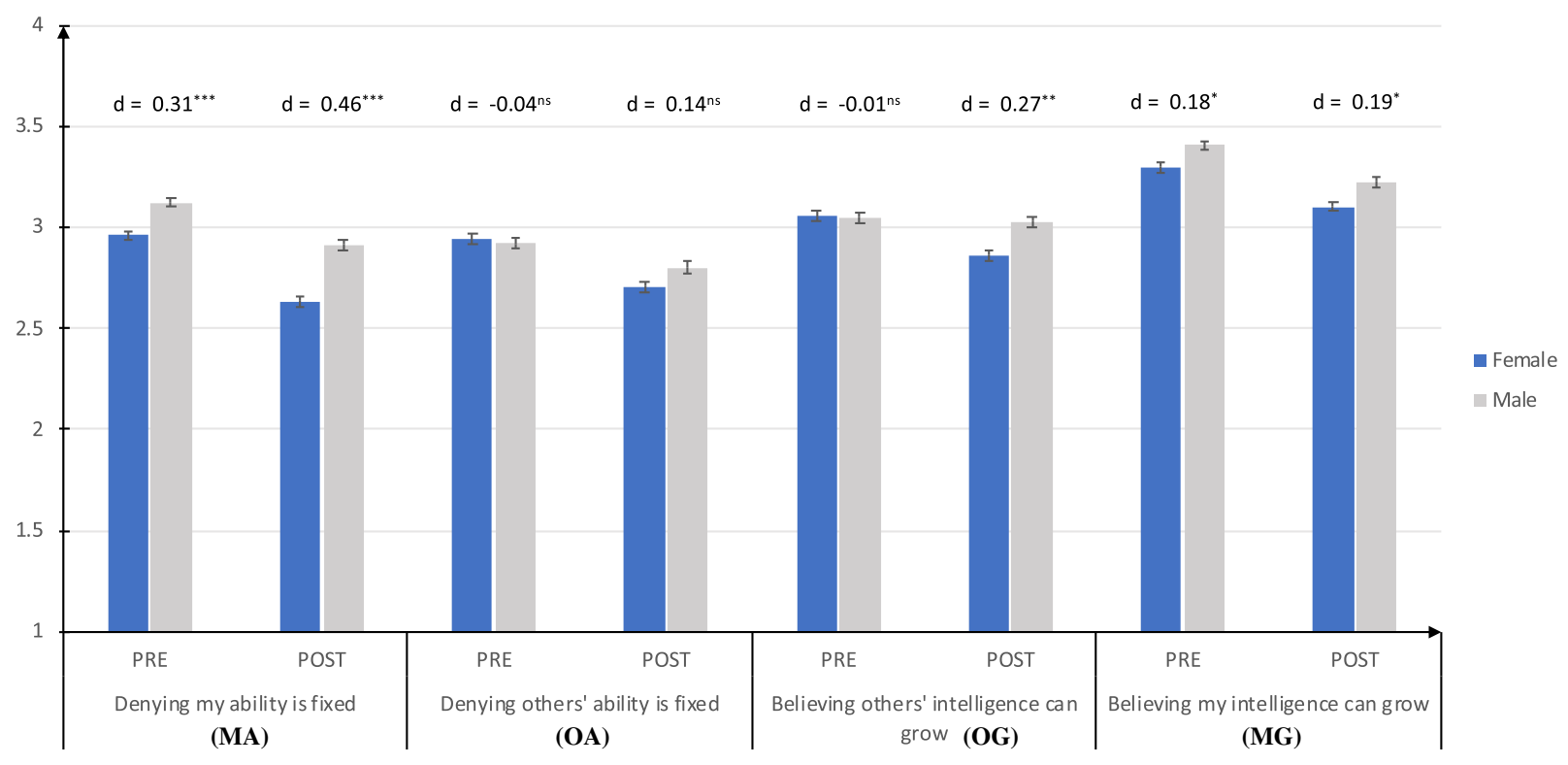

FIG. 4. Mean mindset scores (with SE bars) for female and male students in each mindset group [my ability (MA), others' ability $(\mathrm{OA})$, others' growth (OG), and my growth (MG)] across pre and post for students who took both the pretest and post-test $(N=519)$. Above each pair of bars are the Cohen's $d$ values (positive sign indicates that male students have a higher score than female students), and statistical significance levels used are the following: ${ }^{*}=p<0.05,{ }^{* *}=p<0.01,{ }^{* * *}=p<0.001$, and nonsignificant (ns).

Physics 1 grade had a statistically significantly and moderately sized correlation with pre-college academic scores $(r=0.35$ with HS GPA, and $r=0.47$ with SAT Math). Physics 1 grade exhibited statistically significant correlations with almost all of the mindset constructs at pre, but most of the correlation values were small: pre my ability $r=0.14$ and pre others' ability $r=0.05$.

Multiple regression (using $R$ library [93]) was used to tease apart the independent contributions to grade of the various elements correlated with each other and with grade. In model 1a in Table III, we only ran for the demographic information (gender or sex) to predict Physics 1 grade and found a marginal difference where male students were found to do slightly better than female students with regard to course grades. In model $1 \mathrm{~b}$, Only with Academic Background, we included SAT Math and HS GPA scores without adding gender or sex to examine the predictive strength of these pre-college variables for students' college

TABLE III. Standardized $\beta$ values (along with degrees of freedom and adjust $R^{2}$ ) from multiple regression models predicting Physics 1 grade in which the independent variables are gender or sex, SAT Math, HS GPA, pre mindset constructs, and course sections (estimates of differences in Secs. II-IV, treating Sec. I as the contrast group). Statistically significant values are bolded, where $*=p<0.05$, ${ }^{* *}=p<0.01,^{* * *}=p<0.001$.

\begin{tabular}{|c|c|c|c|c|c|c|c|}
\hline Variables & $\begin{array}{l}\text { Model 1a } \\
\text { (only } \\
\text { gender } \\
\text { or sex) }\end{array}$ & $\begin{array}{l}\text { Model 1b } \\
\text { (only } \\
\text { academic } \\
\text { background) }\end{array}$ & $\begin{array}{l}\text { Model 1c } \\
\text { (only } \\
\text { mindset } \\
\text { groups) }\end{array}$ & $\begin{array}{c}\text { Model } 2 \\
\text { (gender or sex } \\
\text { and academic } \\
\text { background) }\end{array}$ & $\begin{array}{c}\text { Model } 3 \\
\text { (adding the } \\
\text { most significant } \\
\text { mindset group) }\end{array}$ & $\begin{array}{l}\text { Model } 4 \\
\text { (adding all } \\
\text { mindset } \\
\text { groups) }\end{array}$ & $\begin{array}{c}\text { Model } 5 \\
\text { (adding } \\
\text { section as } \\
\text { a variable) }\end{array}$ \\
\hline $\begin{array}{l}\text { Gender or sex } \\
\quad(F=0, M=1)\end{array}$ & $0.07^{*}$ & & & $0.137^{* * *}$ & $0.117^{* *}$ & $0.120^{* *}$ & $0.123^{* *}$ \\
\hline SAT Math & & $0.341^{* * * *}$ & & $0.325^{* * *}$ & $0.335^{* * *}$ & $0.324^{* * *}$ & $0.320^{* * *}$ \\
\hline HS GPA & & $0.354^{* * * *}$ & & $0.383^{* * *}$ & $0.377^{* * *}$ & $0.371^{* * *}$ & $0.369^{* * *}$ \\
\hline Pre my ability & & & $0.156^{* * *}$ & & $0.105^{* * *}$ & $0.111^{*}$ & $0.109^{*}$ \\
\hline Pre my growth & & & 0.006 & & & -0.028 & 0.033 \\
\hline Pre others' ability & & & 0.08 & & & 0.068 & -0.058 \\
\hline Pre others' growth & & & $-0.141^{* *}$ & & & -0.081 & -0.072 \\
\hline Section II & & & & & & & 0.179 \\
\hline Section III & & & & & & & 0.016 \\
\hline Section IV & & & & & & & 0.153 \\
\hline Degree of freedom & 746 & 623 & 636 & 622 & 535 & 527 & 524 \\
\hline Adjusted $R^{2}$ & 0.003 & 0.29 & 0.03 & 0.31 & 0.31 & 0.31 & 0.32 \\
\hline
\end{tabular}


level physics grades. The results show that both of the precollege test scores strongly predict students' course grade in physics. In model 1c, we only included students' mindset scores and found that my ability group had a positive relation with respect to students' grade and the relation was statistically significant $(p<0.001)$. On the other hand, students' beliefs about others' growth had a negative association to Physics 1 grade $(p<0.01)$. In model 2 which combines models $1 \mathrm{a}$ and $1 \mathrm{~b}$, we found that both gender or sex and prior academic skills (SAT Math and HS GPA) were statistically significant to predict Physics 1 grade, and HS GPA was the strongest predictor among three. Despite the small initial gap in students' Physics 1 grade between female and male students, model 2 shows that male students tended to have higher grades in the college level Physics 1 courses than female students after controlling for students' pre-college overall academic preparation. Thus, there was some indication that another factor beyond prior academic performance was related to course performance.

In model 3, when we entered pre my ability as the fourth predictor of Physics 1 grade, the effect of the gender or sex variable decreased but remained statistically significant. The predictive power of HS GPA slightly decreased compared to model 2, while SAT Math's predictor power slightly increased. Overall, SAT Math and HS GPA were still the top two predictors of Physics 1 grade followed by gender or sex and pre my ability.

In model 4, when we added the other three pre mindset constructs (my growth, other's growth, and others' ability), the my ability mindset group was the only statistically significant predictor of course grade among the four mindset constructs. The predictive strengths of the other significant predictors were similar in size to the model 3 values, suggesting robust estimates of the relationships.

Model 5 added course sections as predictors to model 4's variables, but none of the sections turned out to be a significant predictor of course grade. Furthermore, all other predictors were roughly similar in size and statistical significance for model 4 , ruling out section (or instructor) differences as a confounding variable.

\section{GENERAL DISCUSSION}

Many past studies in the physics education literature have reported lower average physics motivational characteristics (e.g., self-efficacy, interest, sense of belonging, identity, etc.) among female students than male students in physics classes $[10,11,27]$ and that these differences persist or become larger even at matched performance levels at the end of the course [29,30]. The novel results of our study show similar differences in a different motivational construct-physics-related mindset, particularly in the my ability dimension. That is, female students in the studied context were more likely to carry beliefs that innate talent was needed for themselves to excel in physics and that they may not have that special talent. Aside from the differences in gender or sex, we also found that pre my ability (denying my ability is fixed) is a stronger predictor of students' Physics 1 grade (see model 1c) compared to other mindset groups. Fixed mindset has been shown to negatively impact students' academic outcomes [94] and our findings are consistent with past studies. The unique contribution of our study is that rather than general beliefs about intelligence referring to others, it appears that more specific beliefs about students' own intelligence or ability in physics may be important to understand the role of mindset in academic settings. In particular, students' achievements in physics can be more connected to the degree to which students are fixed or growth mindset about their own abilities in physics in contrast to general mindset or mindset for others.

Given that gender or sex is still a statistically significant factor in the final model (model 5), there can be other sources and factors that can explain Physics 1 grade differences between female and male students. These sources might include but are not limited to instructional method [12], instructors' level of support or lack thereof [73], biases and discrimination, stereotype threat [26], and lack of role model for students [21]. For instance, online role model intervention done in psychology and chemistry courses helped female students achieve higher grades and lowered their DFW (grades of D, F, or withdrawing from the course) rates [95].

Attaining success in physics is most commonly thought to require a natural ability or is associated with having "innate talent" [45]. These ability-based beliefs about success in physics deny the substantial contribution of study strategies, spending time on the task productively, developing greater level of interest in learning physics, and embracing failures as stepping stones to learning. Historically, well-known physicists have generally been depicted as being geniuses, with little mention of the struggle these physicists had while learning new concepts or how often they had failed before they eventually made a discovery in the field of physics [96]. Likewise, the privilege and advantages that certain groups of scientists have and the gender-based and race-based discriminations others undergo are often overlooked when thinking about the image of a successful physicist [97]. Modern pop culture and media also reinforce the stereotypical image of a physicist as being male and brilliant, such as in the famous TV series "The Big Bang Theory." All these previously portrayed and still ongoing stereotypical beliefs about the brilliance of men continue to impact our students' interactions within the classroom and their beliefs about themselves and also about other students [98]. Though we do not know the sources of it, our results show an increase in the differences for the pre my ability scores between female and male students. Thus, we have reasons to believe that classroom experiences (e.g., from group interactions to one-on-one student-instructor conversations) might shape students' attitudes, including their mindset. 
In general, our results offer an important piece of evidence for the relationship between a specific mindset dimension (my ability) and students' physics grade in calculus-based first year courses. This ability-related and self-focused mindset group also showed sizable gender or sex difference in both pre- and postresults (the gap increases in the post), where women were more likely to adopt a fixed mindset view. In the past studies, having a fixed mindset has been found to yield negative academic outcomes especially for those who are underrepresented in a particular field and may come to college with less prior academic preparation for various reasons [59]. With that in mind, women with a fixed mindset may attribute their struggle to the qualities that they think they cannot change, which may make them less willing and excited about embracing struggle when they encounter difficult problems. For instance, female students, who often do not receive similar encouragement as do male students to enroll in AP Physics classes [99], may associate their feelings of struggle in college-level physics courses with a lack of ability rather than insufficient pre-college academic preparation and the fact that struggle is normal and universal when learning physics and that they will excel if they work hard and work smart using deliberate strategies and taking advantage of all of the resources. An equitable and inclusive learning environment in which all students have a high sense of belonging and are supported in their struggles with learning physics and in which a growth mindset is inculcated is critical. Since the prior literature did not extensively investigate the relation between mindset and gender in the context of physics, our study and findings shed light on this issue and can help instructors with the transformation of the physics classes to make them more equitable and inclusive spaces for historically marginalized groups.

\section{IMPLICATIONS}

Women and minorities in physics and physics-related disciplines experience many barriers at all levels, such as stereotype threat, biases against their ability, etc. Even though there have been increasing efforts to increase diversity and support women in the field, such as by forming Women in Physics committees in many institutions, the discipline of physics is still a majority male population with a masculine culture. Also, many implicit and explicit biases and discriminations against women's retention and advancement still exist. For instance, a few years ago, a male particle physicist giving a talk at a particle physics convention stated that "Physics [is] invented and built by men, it's not by invitation." [100]. Such statements and attitudes are not uncommon and make it very difficult for students from underrepresented groups, e.g., women, to develop higher level of physics motivational beliefs, e.g., about women's capability to excel in physics.
In our findings, students already had different views about their abilities when they arrived in our classrooms: female students had more fixed mindset about their ability compared to male students. Additionally, we found that these initial differences in mindset, particularly in the my ability group, is correlated with students' final grade in the course. For an instructor, there are ways to create equitable and inclusive learning spaces for students so that they are not impacted by these biases and stereotypes and can focus on their own personal growth regardless of their demographic characteristics. The aforementioned belonging-mindset interventions, which do not isolate particular members of a group, i.e., they associate the struggle with the physics discipline rather than with students' identities, can be one great tool to create more equitable and inclusive learning environment and support underrepresented students in physics classrooms. Classroom interventions can be useful particularly for first-year students as in our sample since first-yearcollege experiences may be a determining factor for whether students decide to stay in or exit from a STEM program altogether [101]. Belonging and mindset interventions send messages to all students that struggling and being overwhelmed with first-year-college courses, such as physics, is a very common and normal experience among many students, and one can overcome difficulties and become good at a subject by working hard, working smart (e.g., by using productive study strategies and taking advantage of the resources including instructor, teaching assistant and peers) and embracing failures as learning opportunities [70]. This is an especially valuable message for the underrepresented students because they can internalize their struggle with their identity as a sign of not fitting in [20]. These experiences can then result in disengagement from the course activities which may lead to lower performance on assessments, or dropping the course or exiting from a STEM track altogether [102].

While some campus trainings for faculty and graduate students have begun to include pedagogical strategies around "growth mindset" at a very broad level, previous work shows that mindset beliefs can vary from discipline to discipline [45]. Every department and field has a different culture and challenges to work on, and physics, in that sense, has greater challenges than many other disciplines due to the stereotypes and biases and lack of diversity. Physics has been one of the few disciplines that still continues to be very homogenous in terms of gender, race, parental education, social class, etc. It is also one of the few disciplines in physical sciences that is considered as requiring "brilliance" to succeed [45]. That is why, social belonging and growth mindset interventions and associated training need to be tailored specifically to physics in order 
to address its unique challenges. To our knowledge, this study was one of the very few studies in the physics education research focusing on students' mindset views and how it relates to learning outcomes, academic prior scores, and gender or sex. In our previous work, we carried out social-belonging and mindset intervention and observed a decrease in gender gap in students' physics grades in the intervention group, whereas the gap remained in the control group [70].

As previous research showed, instructors play a tremendous role in impacting students' identities in the classroom [73]. Not only students' mindset, but also instructors' mindset views (i.e., whether they have growth or fixed mindset about their students' potential) can impact students' performance especially for underrepresented student groups [75]. Our study shows evidence that students' mindset can change, particularly for women, in one semester of instruction. This change, however, is in the negative direction such that female students believed that their physics ability is fixed. Our data are limited to explore further the reasons for that shift but we hypothesize that the classroom culture and instructors' level of engagement particularly with equity and inclusion as potential sources of the increase in these gaps. In particular, as physics instructors, our teaching goals should also focus on helping students become more growth mindset and gain confidence in their skills. To achieve this, we need to adopt more equitable and inclusive pedagogical tools and incorporate growth mindset methods tailored to each individual classroom. For instance, designing a more growth mindset syllabi and "first-day-of-class" speech, and telling students that "making mistakes is okay and part of the learning process" can be some of the ways to accomplish this goal $[54,55]$. Additionally, many students can hesitate to promptly answer questions asked in the class because they may worry about appearing unintelligent. Furthermore, hesitation about asking questions in the classroom can turn into a negative feedback loop: the less a student asks questions they have, the more they have gaps in their understanding, and then they try less to engage with instructor and the materials in the following classes. In order to eliminate these concerns, which act as barriers to students' participation and learning, instructors need to create an equitable and inclusive learning environment and assure students that making mistakes is part of the learning process and constructing a robust knowledge structure.

Students' mindset beliefs can also shift based on their interactions with peer groups. In our data set, we find that female students shifted toward "believing my ability is fixed" end of the spectrum. In all types of classrooms, more so in the active-engagement classes, students often do collaborative work and have peer discussion. Our previous study in college calculus-based introductory physics discussed here showed that women are less likely to think that their peers see them as someone who is good at physics [103]. Having positive recognition from others or not can also relate to how students see themselves in terms of their physics ability. It is also important to broaden the strategies in the classroom discussions so that students from all demographic groups can have an opportunity to participate equitably. For instance, when the instructors do not wait for a certain time or select the student who first raises their hand, students' perceptions and willingness to participate can be influenced and some students from the dominant group will dominate the discussions. For example, in one such classroom, researchers found that outspokenness of some students can affect other students" views about "who is good" in the subject and can reinforce bias towards female students, which can in turn negatively impact their performance [98]. Therefore, instructors need to be more mindful of creating an inclusive and respectful classroom culture so that all students can fully engage at a learning task or class activity rather than some students having anxiety about participating or being disregarded or devalued by their peers or the instructor.

Finally, in physics education, there is growing interest and research in using motivational factors to explain student learning and retention. However, mindset research in physics context has recently joined these efforts and few such studies have been conducted $[47,48,104]$. We hope that our work will motivate future work and direct attention to the mindset aspect of student learning in efforts to enhance diversity, equity, and inclusion in physics.

\section{FUTURE DIRECTIONS AND LIMITATIONS}

Although students, in general, value the contribution of effort to be successful in physics, they might think that natural ability in physics remains a stronger determinant of one's success and the extent to which the person can excel in physics. This aspect can be especially critical for physics due to societal stereotypes and it can be more detrimental to minoritized groups' achievements. Since we find that the my ability mindset construct had correlation with students' course grade among all mindset constructs, more studies are needed to unpack this specific dimension. Future work could include more items for each quadrant with both regular and reverse coded items.

In this study, we only focused on students' mindset and performance comparing female and male students. Although our data show a direct relation between physics learning and specific mindset constructs in physics, it would be useful to explore why these differences in ability-related mindset construct appear and how such a gap can impact students' other motivational characteristics, such as self-efficacy or sense of belonging. We also note that causality between mindset and performance has not yet 
been established by our correlational study, although other intervention work does suggest the relationship is casual [105]. We need to do further work to show that it is the fixed ability about self that is a particularly important driver of performance gaps.

Furthermore, the degree to which students receive recognition from their instructors or graduate teaching assistants can also impact their mindset views. Equally importantly, equity issues and mindset differences can be more salient at the intersection of race and gender [106]; therefore we plan to further our research in the future by looking at different student demographics from an intersectional perspective. As a final note, testing the generalizability of our results to other populations (other teaching methods, other physics courses, or other colleges and universities with different demographics and sizes) can also be useful to obtain a broader understanding of students' intelligence mindset.

\section{ACKNOWLEDGMENTS}

This work was supported by Grant No. DUE-1524575 from the National Science Foundation and Grant No. 220020483 from the James S. McDonnell Foundation. We would like to thank the anonymous reviewers for their time, careful reading of our manuscript, and their many insightful comments and suggestions.

\section{APPENDIX: PHYSICS INTELLIGENCE MINDSET SURVEY}

In this section we describe some method and measurement related aspects of our study. Table IV shows the physics intelligence mindset items. Table $\mathrm{V}$ and Fig. 5 provide further information about the descriptives of our survey results for pre and post scores.

TABLE IV. The physics intelligence mindset questions. The responses are on a Likert scale from 1-4.

Q1. Anyone can become good at solving physics problems through hard work.

Q2. Only a few specially qualified people are capable of really understanding physics.

Q3. No matter who you are, you can change your intelligence in physics quite a lot.

Q4. To really excel in physics, a person needs to have a natural ability in physics

Q5. If I really have to struggle to solve physics problems, that means I'm just not a physics person.

Q6. If I spend a lot of time working on difficult physics problems, I can develop my intelligence in physics.

Q7. If I make mistakes on physics assignments and exams, I think that maybe I'm just not smart enough to excel in physics.

TABLE V. The mean scores of each mindset group for pre and post across gender or sex are presented in this table. The table also demonstrates these values for (A) all the students who took the pre- and or postsurvey, (B) only students who took both pre and post. Higher scores indicate more growth mindset and less fixed mindset views. $N$ is the number of students.

\begin{tabular}{|c|c|c|c|c|c|c|c|}
\hline & & \multicolumn{3}{|c|}{ (A) For all students } & \multicolumn{3}{|c|}{ (B) Students who took both pre and post } \\
\hline & & Overall mean & Female mean & Male mean & Overall mean & Female mean & Male mean \\
\hline \multirow[t]{4}{*}{ PRE } & My ability & 3.05 & 2.96 & 3.12 & 3.07 & 2.94 & 3.16 \\
\hline & Others' ability & 2.93 & 2.95 & 2.92 & 2.94 & 2.94 & 2.94 \\
\hline & My growth & 3.36 & 3.30 & 3.41 & 3.36 & 3.28 & 3.42 \\
\hline & Others' growth & 3.05 & 3.06 & 3.04 & 3.03 & 3.02 & 3.04 \\
\hline \multirow[t]{5}{*}{ POST } & My ability & 2.80 & 2.63 & 3.91 & 2.81 & 2.66 & 3.92 \\
\hline & Others' ability & 2.76 & 2.71 & 2.80 & 2.76 & 2.72 & 2.79 \\
\hline & My growth & 3.18 & 3.10 & 3.22 & 3.19 & 3.12 & 3.21 \\
\hline & Others' growth & 2.96 & 2.86 & 3.02 & 2.97 & 2.90 & 3.03 \\
\hline & $N$ & \multicolumn{3}{|c|}{ Ranging from 633 to 654} & \multicolumn{3}{|c|}{ Complete cases: 519} \\
\hline
\end{tabular}




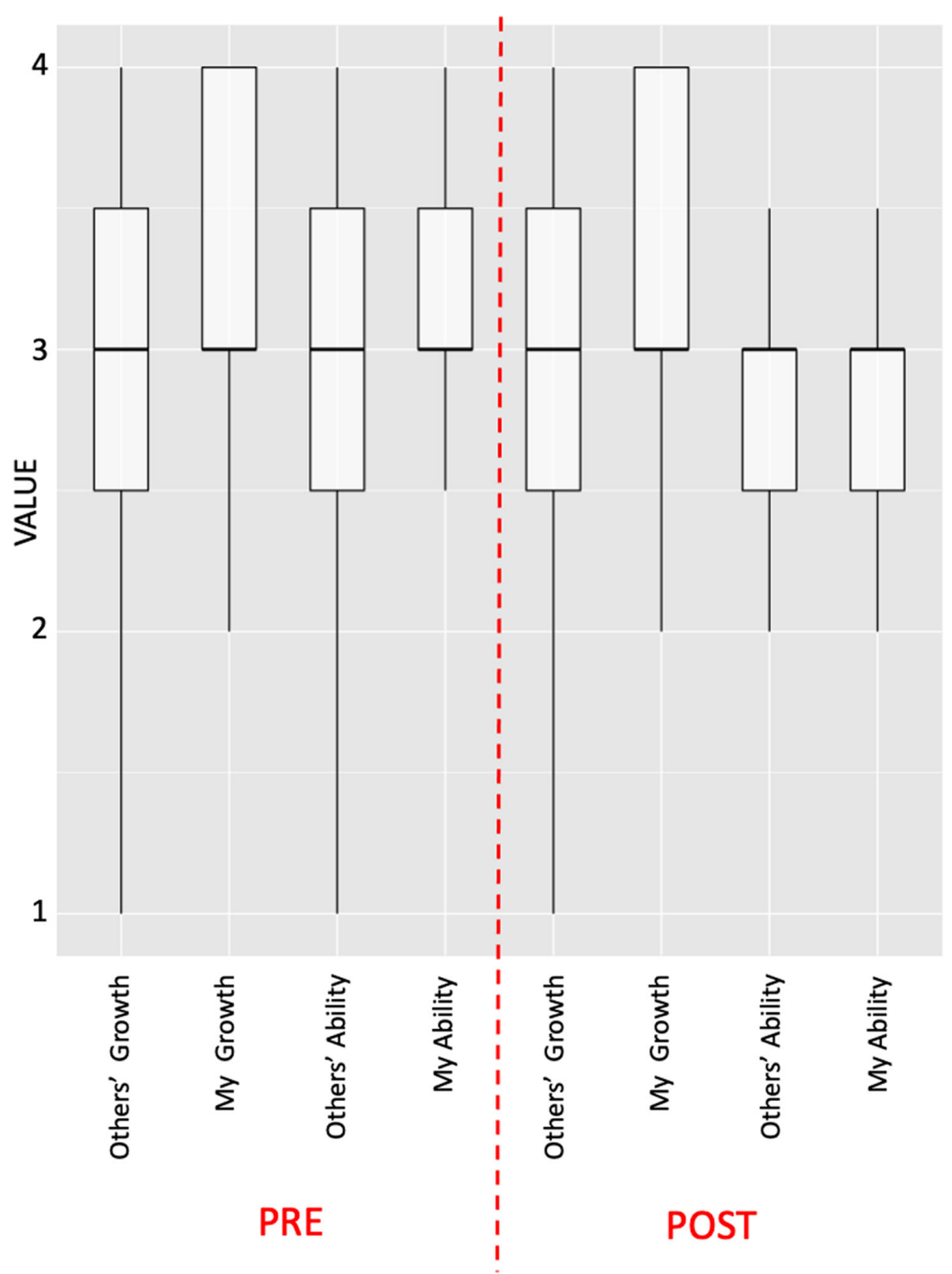

FIG. 5. Box plots for all pre and post mindset constructs demonstrate "minimum," first quartile (25th percentile), median, third quartile (75th percentile), and "maximum" values.

[1] National Student Clearinghouse Research Center, Science and Engineering Degree Attainment: 20042014 retrieved from https://nscresearchcenter.org/ snapshotreport-degreeattainment15/ (2015).

[2] National Science Board Science and Engineering Indicators, National Science Foundation Report, retrieved from https:/www.nsf.gov/statistics/2018/nsb20181/digest/ sections/preface.

[3] https://www.aip.org/statistics/data-graphics/percent-physicsbachelors-and-phds-earned-women-classes-1975-through2016.
[4] Women, Minorities, and Persons with Disabilities in Science, and Engineering, retrieved from https://nsf .gov/statistics/2017/nsf17310/digest/occupation/women .cfm (2017).

[5] K. M. Whitcomb, Z. Y. Kalender, T. J. Nokes-Malach, C. D. Schunn, and C. Singh, Comparison of self-efficacy and performance of engineering undergraduate women and men, Int. J. Engin. Educ. 36, 1996 (2020), https:// www.ijee.ie/1atestissues/Vol36-6/24_ijee4004.pdf.

[6] R. E. O'Dea, M. Lagisz, M. D. Jennions, and S. Nakagawa, Gender differences in individual variation 
in academic grades fail to fit expected patterns for STEM, Nat. Commun. 9, 3777 (2018).

[7] J.E. Watkins, Examining issues of underrepresented minority students in introductory physics, Ph.D. thesis, Doctoral dissertation, Harvard University, 2010.

[8] L. Kost, S. Pollock, and N. Finkelstein, Characterizing the gender gap in introductory physics, Phys. Rev. ST Phys. Educ. Res. 5, 010101 (2019).

[9] L. Kost, S. Pollock, and N. Finkelstein, Gender disparities in second-semester college physics: The incremental effects of a "smog of bias", Phys. Rev. ST Phys. Educ. Res. 6, 020112 (2010).

[10] J. M. Nissen and J. T. Shemwell, Gender, experience, and self-efficacy in introductory physics, Phys. Rev. Phys. Educ. Res. 12, 020105 (2016).

[11] V. Sawtelle, E. Brewe, and L. Kramer, Exploring the relationship between self-efficacy and retention in introductory physics, J. Res. Sci. Teach. 49, 1096 (2012).

[12] E. Brewe, V. Sawtelle, L. H. Kramer, G. E. O'Brien, I. Rodriguez, and P. Pamelá, Toward equity through participation in Modeling Instruction in introductory university physics, Phys. Rev. ST Phys. Educ. Res. 6, 010106 (2010).

[13] S. Salehi, E. Burkholder, P. Lepage, S. Pollock, and C. Wieman, Demographic gaps or preparation gaps?: The large impact of incoming preparation on performance of students in introductory physics, Phys. Rev. ST Phys. Educ. Res. 15, 020114 (2019).

[14] P. M. Sadler and R. H. Tai, Success in introductory college physics: The role of high school preparation, Sci. Educ. 85, 111 (2001).

[15] T. J. Nokes-Malach, Z. Y. Kalender, E. Marshman, C. D. Schunn, and C. Singh, Prior preparation and motivational characteristics mediate relations between gender and learning outcomes in introductory physics, Proceedings of the Physics Education Research Conference 2018, Washington, DC, edited by A. Traxler, Y. Cao, and S. Wolf (AIP, New York, 2019), 10.1119/perc.2018.pr .Nokes-Malach.

[16] L. E. Kost, S. J. Pollock, and N. D. Finkelstein, Characterizing the gender gap in introductory physics, Phys. Rev. Phys. Educ. Res. 5, 010101 (2009).

[17] N. I. Karim, A. Maries, and C. Singh, Do evidencebased active-engagement courses reduce the gender gap in introductory physics, Eur. J. Phys. 39, 025701 (2018).

[18] A. Maries, N. I. Karim, and C. Singh, Is agreeing with a gender stereotype correlated with the performance of female students in introductory physics?, Phys. Rev. Phys. Educ. Res. 14, 020119 (2018).

[19] N. M. Hewitt and E. Seymour, A long, discouraging climb, ASEE Prism 1, 24 (1992).

[20] E. Seymour and N. M. Hewitt, Talking about Leaving: Why Undergraduates Leave The Sciences (Westview Press, Boulder, CO 1997).

[21] S. Cheryan, S. A. Ziegler, A. Montoya, and L. Jiang, Why are some STEM fields more gender balanced than others?, Psychol. Bull. 143, 1 (2017).
[22] S. L. Eddy and S. E. Brownell, Beneath the numbers: A review of gender disparities in undergraduate education across science, technology, engineering, and math disciplines, Phys. Rev. Phys. Educ. Res. 12, 020106 (2016).

[23] A. Madsen, S. B. McKagan, and E. C. Sayre, Gender gap on concept inventories in physics: What is consistent, what is inconsistent, and what factors influence the gaps?, Phys. Rev. Phys. Educ. Res. 9, 020121 (2013).

[24] P. Labudde, W. Herzog, M. P. Neuenschwander, E. Violi, and C. Gerber, Girls and physics: Teaching and learning strategies tested by classroom interventions in grade, Int. J. Sci. Educ. 22, 143 (2000).

[25] A. Traxler, R. Henderson, J. Stewart, G. Stewart, A. Papak, and R. Lindell, Gender fairness within the force concept inventory, Phys. Rev. Phys. Educ. Res. 14, 010103 (2018).

[26] G. C. Marchand and G. Taasoobshirazi, Stereotype threat and women's performance in physics, Int. J. Sci. Educ. 35, 3050 (2013).

[27] E. Marshman, Z. Y. Kalender, C. Schunn, T. NokesMalach, and C. Singh, A longitudinal analysis of students' motivational characteristics in introductory physics courses: Gender differences, Can. J. Phys. 96, 391 (2018).

[28] T. J. Nokes-Malach, E. Marshman, Z. Y. Kalender, C. Schunn, and C. Singh, Investigation of male and female students' motivational characteristics throughout an introductory physics course sequence, Proceedings of the Physics Education Research Conference 2017, Cinncinnati, OH (AIP, New York, 2018), 10.1119/perc .2017.pr.064.

[29] E. Marshman, Z. Y. Kalender, T. Nokes-Malach, C. Schunn, and C. Singh, Female students with A's have similar self-efficacy as male students with C's in introductory courses: A cause for alarm?, Phys. Rev. Phys. Educ. Res. 14, 020123 (2018).

[30] Z. Y. Kalender, E. Marshman, T. Nokes-Malach, C. Schunn, and C. Singh, Large gender differences in physics self-efficacy at equal performance levels: A warning sign?, Proceedings of the Physics Education Research Conference 2018, Washington, DC(AIP, New York, 2018), 10.1119/perc.2018.pr.Kalender.

[31] Z. Hazari, R. H. Tai, and P. M. Sadler, Gender differences in introductory university physics performance: The influence of high school physics preparation and affective factors, Sci. Educ. 91, 847 (2007).

[32] T. Bouffard-Bouchard, S. Parent, and S. Larivee, Influence of self-efficacy on self-regulation and performance among junior and senior high-school aged students, Int. J. Behav. Dev. 14, 153 (1991).

[33] M. Wang and J. Degol, Motivational pathways to STEM career choices: Using expectancy-value perspective to understand individual and gender differences in STEM fields, Dev Rev. 33, 304 (2013).

[34] B. Zimmerman, D. H. Schunk, and M. K. Dibenedetto, The role of self-efficacy and related beliefs in selfregulation of learning and performance, in Handbook of Competence and Motivation, 2nd ed., edited by 
A. Elliot, C. S. Dweck, and D. S. Yeager (The Guilford Press, New York, 2018).

[35] P. Pintrich and E. De Groot, Motivational and selfregulated learning components of classroom academic performance, J. Educ. Psychol. 82, 33 (1990).

[36] B. Zimmerman, Self-efficacy: An essential motive to learn, Contemp. Educ. Psychol. 25, 82 (2000).

[37] D. Schunk and F. Pajares, The development of academic self-efficacy, in Development of Achievement Motivation, A Volume in The Educational Psychology Series, edited by A. Wigfield and J. Eccles (Academic Press, San Diego, CA, 2002), pp. 15-31.

[38] S. L. Britner, Motivation in high school science students: A comparison of gender differences in life, physical, and earth science classes, J. Res. Sci. Teach. 45, 955 (2008).

[39] C. Dweck, Mindset: The New Psychology of Success (Ballentine, New York, 2006); C. Dweck, Self-Theories: Their Role in Motivation, Personality, and Development (Psychology Press, Philadelphia, 1999).

[40] L. B. Limeri, N. T. Carter, H. G. Harper, H. R. Martin, A. Benton, and E. L. Dolan, Growing a growth mindset: Characterizing how and why undergraduate students' mindset change, Int. J. STEM Educ. 7, 35 (2020).

[41] C. Dweck, Is math a gift? Beliefs that put females at risk, in Why Aren't More Women in Science? Top Researchers Debate the Evidence, edited by S.J. Ceci and W. M. Williams (American Psychological Association, Washington, DC, 2007), p. 47-55.

[42] C. Dweck, Mindsets and math/science achievement, Commission on Mathematics and Science Education (Carnegie Corporation of New York, Institute for Advanced Study, New York 2008).

[43] K. Kricorian, M. Seu, D. Lopez, E. Ureta, and O. Equils, Factors influencing participation of underrepresented students in STEM fields: matched mentors and mindsets, Int. J. STEM Educ. 7, 16 (2020).

[44] D. S. Yeager, G. M. Walton, S. T. Brady, E. N. Akcinar, D. Paunesku, L. Keane, D. Kamentz et al., Teaching a lay theory before college narrows achievement gaps at scale, Proc. Natl. Acad. Sci. U.S.A. 113, E3341 (2016).

[45] S. J. Leslie, A. Chimpian, M. Meyer, and E. Freeland, Expectations of brilliance underlie gender distributions across academic disciplines, Science 347, 262 (2015).

[46] A. Kaijanaho and V. Tirronen, Fixed versus growth mindset does not seem to matter much: A prospective observational study in two late bachelor level computer science courses, Proceedings of the 2018 ACM Conference on International Computing Education Research (Association for Computing Machinery, 2018), pp. 11-20.

[47] A. Little, B. Humphrey, A. Green, A. Nair, and V. Sawtelle, Exploring mindset's applicability to students' experiences with challenge in transformed college physics courses, Phys. Rev. Phys. Educ. Res. 15, 010127 (2019); A. Little, V. Sawtelle, and B. Humphrey, Mindset in context: developing new methodologies to study mindset in interview data, Proceedings of the 2016 Physics Education Research Conference, Sacramento, CA (AIP, New York, 2018), pp. 204-207.
[48] R. E. Scherr, M. Plisch, K. E. Gray, G. Potvin, and T. Hodapp, Fixed and growth mindsets in physics graduate admissions, Phys. Rev. Phys. Educ. Res. 13, 020133 (2017).

[49] I. Rodriguez, E. Brewe, V. Sawtelle, and L. H. Kramer, Impact of equity models and statistical measures on interpretations of educational reform, Phys. Rev. ST Phys. Educ. Res. 8, 020103 (2012).

[50] Z. C. Schudson, Psychologies Stewardship of Gender/ Sex, Perspectives Psychol. Science 16, 1105 (2021).

[51] D. S. Yeager, P. Hanselman, R. Crosnoe, and C. Muller, Changing US students' mindsets about learning improves academic achievement, PRC Res. Brief (2019), https:// repositories.lib.utexas.edu/bitstream/handle/2152/75735/ prc-brief-4-07-yeager-growth-mindset.pdf?sequence=2.

[52] J. G. Nicholls, Achievement and motivation: Conceptions of ability, subjective experience, task choice, and performance, Psychol. Rev. 91, 328 (1984).

[53] K. Muenks and D. B. Miele, Students' thinking about effort and ability: The role of developmental, contextual, and individual difference factors, Rev. Educ. Res. 87, 707 (2017).

[54] D. S. Yeager, D. Paunesku, G. M. Walton, and C. S. Dweck, How can we instill productive mindsets at scale? A review of the evidence and an initial $R \& D$ agenda: White paper prepared for the White House meeting on "Excellence in Education: The Importance of Academic Mindsets" (2013).

[55] D. S. Yeager and C.S. Dweck, Mindsets that promote resilience: When students believe that personal characteristics can be developed, Educ. Psychol. 47, 302 (2012).

[56] S. Beilock, W. Jellison, R. Rydell, A. McConnell, and T. Carr, On the causal mechanisms of stereotype threat: Can skills that don't rely heavily on working memory still be threatened?, Pers. Soc. Psychol. Bull. 32, 1059 (2006).

[57] S. Beilock, R. Rydell, and A. McConnell, Stereotype threat and working memory: Mechanisms, alleviations, and spillover, J. Exp. Psychol. Gen. 136, 256 (2007).

[58] M. W. Eysenck and M. G. Calvo, Anxiety and performance: The processing efficiency theory, Cognition and emotion 6, 409 (1992).

[59] C. S. Dweck and E. L. Leggett, A social-cognitive approach to motivation and personality, Psychol. Rev. 95, 256 (1988).

[60] S. Upson and L.F. Friedman, Where are the female geniuses?, Scientific Am. Mind 23, 63 (2012), https:// www.scientificamerican.com/article/where-are-all-thefemale-geniuses $1 /$.

[61] L. Bian, S. J. Leslie, and A. Chimpian, Gender stereotypes about intellectual ability emerge early and influence children's interest, Science 355, 389 (2017).

[62] J. Aronson, C. B. Fried, and C. Good, Reducing the effects of stereotype threat on African American college students by shaping theories of intelligence, J. Exp. Soc. Psychol. 38, 113 (2002).

[63] C. Good, J. Aronson, and M. Inzlicht, Improving adolescents' standardized test performance: An intervention to reduce the effects of stereotype threat, J. Appl. Dev. Psychol. 24, 645 (2003). 
[64] L. S. Blackwell, K. H. Trzesniewski, and C. S. Dweck, Implicit theories of intelligence predict achievement across an adolescent transition: A longitudinal study and an intervention, Child Development 78, 246 (2007).

[65] V. F. Sisk, A. P. Burgoyne, J. Sun, J. L. Butler, and B. N. Macnamara, To what extent and under which circumstances are growth mind-sets important to academic achievement? Two meta-analysis, Psychol. Sci. 29, 549 (2018).

[66] D. S. Yeager and G. M. Walton, Social-psychological interventions in education: They are magic, Rev. Educ. Res. 81, 267 (2011).

[67] G. M. Walton, C. Logel, J. M. Peach, S. J. Spencer, and M. P. Zanna, Two brief interventions to mitigate a "chilly climate" transform women's experience, relationship, and achievement in engineering, J. Educ. Psychol. 107, 468 (2015).

[68] D. Paunesku, G. M. Walton, C. Romero, E. N. Smith, D. S. Yeager, and C. S. Dweck, Mind-set interventions are a scaleable treatment for academic underachievement, Psychol. Sci. 26, 784 (2015).

[69] A. Miyake, L. E. Kost-Smith, N. D. Finkelstein, S. J. Pollock, and G. L. Cohen, Reducing the gender achievement gap in college science: A classroom study of values affirmation, Science 330, 1234 (2010).

[70] K. Binning, N. Kaufmann, E. McGreevy, O. Fotuhi, Susie Chen, E. Marshman, Z. Y. Kalender, L. Limeri, L. Betancur, and C. Singh, Changing social contexts to foster equity in college science courses: An ecological-belonging intervention, Psychol. Sci. 31, 1059 (2020).

[71] L. E. Kost-Smith, S. J. Pollock, N. D. Finkelstein, G. L. Cohen, T. A. Ito, and A. Miyake, Replicating a SelfAffirmation Intervention to Address Gender Differences: Successes and Challenges, AIP Conf. Proc. 1413, 231 (2012).

[72] P. A. O'Keefe, A. Ben-Eliyahu, and L. LinnenbrinkGarcia, Shaping achievement goal orientations in a mastery-structured environment and concomitant changes in related contingencies of self-worth, Motivation and emotion 37, 50 (2013).

[73] Z. Hazari, C. Cass, and C. Beattie, Obscuring power structures in the physics classroom: Linking teacher positioning, student engagement, and physics identity development, J. Res. Sci. Teach. 52, 735 (2015).

[74] A. Rattan, C. Good, and C. S. Dweck, "It's ok-Not everyone can be good at math": Instructors with an entity theory comfort (and demotivate) students, J. Exp. Soc. Psychol. 48, 731 (2012).

[75] E. A. Canning, K. Muenks, D. J. Green, and M. C. Murphy, STEM faculty who believe ability is fixed have larger racial achievement gaps and inspire less student motivation in their classes, Sci. Adv. 5, 4734 (2019).

[76] A. J. Elliot and J. M. Harackiewicz, Approach and avoidance goals and intrinsic motivation: A mediation analysis, J. Personality Social Psychol. 70, 461 (1996).

[77] R. E. Keller, E. Johnson, and S. DeSchong, A structural equation modeling looking at students' participatory behavior and their success in Calculus I, Int. J. STEM Educ. 4, 24 (2017).

[78] J. M. Cortina, What is coefficient alpha? An examination of theory and applications, J. Appl. Psychol. 78, 98 (1993).

[79] C. Ames, Classrooms: Goals, structures, and student motivation, J. Educ. Psychol. 84, 261 (1992).

[80] C. Senko, C. S. Hulleman, and J. M. Harackiewicz, Achievement goal theory at the crossroads: Old controversies, current challenges, and new directions, Educ. Psychol. 46, 26 (2011).

[81] I. Borg and P. Groenen, Modern Multidimensional Scaling: Theory and Applications, 2nd ed. (SpringerVerlag, New York, 2005), pp. 207-212.

[82] T. F. Cox and M. A. Cox, Multidimensional scaling, in Handbook of Data Visualization, Spring Handbook Comp. Statistics (Springer, Berlin, Heidelberg, 2008), pp. 315-347.

[83] A. Traxler, X. Cid, J. Blue, and R. Barthelemy, Enriching gender in physics education research: A binary past and a complex future, Phys. Rev. Phys. Educ. Res. 12, 020114 (2016).

[84] J. Roy, Engineering by numbers, https://ira.asee.org/wpcontent/uploads/2019/07/2018-Engineering-by-NumbersEngineering-Statistics-UPDATED-15-July-2019.pdf.

[85] E. Redish, J. Saul, and R. Steinberg, Student expectations in introductory physics, Am. J. Phys. 66, 212 (1998).

[86] D. Ghosh and A. Vogt, Outliers: An evaluation of methodologies, in Joint Statistical (2012), Vol. 2012.

[87] D. Kennedy, J. Lakonishok, and W. H. Shaw, Accommodating outliers and nonlinearity in decision models, J. Account. Audit. Finance. 7, 161 (1992).

[88] K. M. Whitcomb, Z. Y. Kalender, T. J. Nokes-Malach, C. D. Schunn, and C. Singh, Engineering students' performance in foundational courses as a predictor of future academic success, Int. J. Engin. Educ. 36, 1340 (2020), https://www.lrdc.pitt.edu/SCHUNN/ papers/WhitcombetlalFoundationsIJEE2020.pdf.

[89] A. Bandura, Self-efficacy, in Encyclopedia of Psychology, 2nd ed., edited by R. J. Corsini (Wiley, New York 1994), Vol. 3, pp. 368-369.

[90] S. Cotner and C. J. Ballen, Can mixed assessment methods make biology classes more equitable?, PLoS One 12, e0189610 (2017).

[91] J. B. Kruskal, Multidimensional scaling by optimizing goodness of fit to a nonmetric hypothesis, Psychometrika 29, 1 (1964).

[92] J. Cohen, Statistical Power Analysis for the Behavioral Sciences (Routledge Academic, New York, NY, 1988).

[93] R Documentation, Fitting Linear Models https:// www.rdocumentation.org/packages/stats/versions/3.6.2/ topics/lm.

[94] N. Hwang, M. Reyes, and J. S. Eccless, Who holds a fixed mindset and whom does it harm in mathematics?, Youth Soc. 51, 247 (2019).

[95] S. D. Herrmann, R. M. Adelman, J. E. Bodford, O. Graudejus, M. A. Okun, and V.S. Y. Kwan, The Effects of a female role model on academic performance and persistence of women in STEM courses, Basic Applied 
Social Psychol. 38, 258 (2016), https://files.eric.ed.gov/ fulltext/ED577154.pdf.

[96] M. Balter, Why Einstein was a genius?, Science (2012), https://www.sciencemag.org/news/2012/11/why-einsteinwas-genius (Accessed: 10 February 2021).

[97] D. W. Chambers, Stereotypic images of the scientist: The draw-a-scientist test, Sci. Educ. 67, 255 (1983).

[98] D. Z. Grunspan, S. L. Eddy, S. E. Brownell, B. L. Wiggins, A.J. Crowe, and S. M. Goodreau, Males under-estimate academic performance of their female peers in undergraduate biology classrooms, PLoS One 11, e0148405 (2016).

[99] C. Day, Female friendly physics first, Phys. Today (2011), https://physicstoday.scitation.org/do/10.1063/PT .5.010135/full/ (Accessed: 10 February 2021).

[100] A. Strumia, Experimental test of a new global discrete symmetry, https://alessandrostrumiahome.files.wordpress .com/2019/03/strumiagenderslidescern.pdf, (2018).

[101] R. M. Felder, G. N. Felder, M. Mauney, C. E. Hamrin, Jr., and E. J. Dietz, A longitudinal study of student performance and retention. III. Gender differences in student performance and attitude, J. Engin. Educ. 84, 151 (1995).
[102] J. P. Holden and E. Lander, Engage to excel: Producing one million additional college graduates with degrees in science, technology, engineering, and mathematics, in Report to the President, edited by President's Council of Advisors on Science and Technology (Executive Office of the President, Washington, DC, 2012), p. vi.

[103] Z. Y. Kalender, E. Marshman, C. D. Schunn, T. J. Nokes-Malach, and C. Singh, Phys. Rev. Phys. Educ. Res. 15, 020119 (2019).

[104] C. Kepple, M. Tilahun, N. Matti, and K. Coble, Pedagogy training for the development of GTA mindsets and inclusive teaching practices, in Proceedings of the 2020 Physics Education Research Conference, virtual conference (AIP, New York, 2020), pp. 272-277.

[105] C. M. Mueller and C. S. Dweck, Praise for intelligence can undermine children's motivation and performance, J. Personality Social Psychol. 75, 33 (1998).

[106] B. Van Dusen and J. Nissen, Equity in college physics student learning: A critical quantitative intersectionality investigation, J. Res. Sci. Teach. 57, 33 (2020). 